\title{
Factors Associated with Alcohol Intake in Mountain Top Huts Among Slope Tourers
}

\author{
Anika Frühauf, Gerhard Ruedl, Christian Kickenweiz, Sepp Thöni, \\ and Martin Kopp
}

\begin{abstract}
Introduction: Ski touring along ski slopes (slope touring) has increased in recent years on Austrian ski slopes. Alcohol consumption is proposed to be a risk factor in winter sports-related accidents. The aim of this study was to evaluate factors associated with alcohol intake among uninjured slope tourers.

Methods: A total of 328 slope tourers (45\% females) with a mean age of $43.8 \pm 11.8$ years were questioned in February and March 2014 in two huts at the top of two Austrian ski areas. Questionnaires were conducted during daytime (9.00 a.m.-4.00 p.m.) and nighttime hours (5.00 p.m.-9.45 p.m.) with a following breath alcohol test. Slope tourers filled in on demographics, skill level, risk-taking behavior, ski helmet use, and alcohol consumption. In addition, slope tourers who had consumed alcohol were asked to estimate their individual breath alcohol level.

Results: In total, 187 (57\%) of the slope tourers reported that they had consumed alcohol at the hut. Male sex, a higher BMI, more ski touring experience, and less ski helmet use were significantly associated with alcohol intake among slope tourers. Mean-tested breath alcohol level was $0.24 \pm 0.17 \%$; this significantly differed from the mean estimated breath alcohol level of $0.18 \pm 0.12 \%$. Male slope tourers had a significantly higher breath alcohol level than female slope tourers $(0.26 \pm 0.17$ vs. $0.22 \pm 0.15 \%$ o $p=0.014)$.

Conclusion: Approximately $60 \%$ of interviewed slope tourers, predominantly males, consumed alcohol in the huts. In addition, male slope tourers had a significantly higher breath alcohol level compared to female slope tourers and mean-tested breath alcohol level was underestimated by approximately $25 \%$ on average.
\end{abstract}

Keywords Ski touring $\bullet$ Slope touring $\bullet$ Alcohol consumption $\bullet$ Risk factors

\footnotetext{
A. Frühauf, M.Sc. $(\varangle) \bullet$ G. Ruedl $\bullet$ C. Kickenweiz $\bullet$ S. Thöni $\bullet$ M. Kopp

Department of Sport Science, University of Innsbruck,

Fürstenweg 185, 6020 Innsbruck, Austria

e-mail: anika.fruehauf@uibk.ac.at
} 


\section{Introduction}

In the Austrian mountainous regions alone, there is an estimated number of eight million ski visitors per year [1]. Slope touring (= the ascending of a ski slope with ski touring equipment and following downhill skiing on the slope) has increased throughout the years with an estimated number of 80,000 slope tourers on Austrian ski slopes per year [2]. The region around the city of Innsbruck hosts approximately 30,000 slope tourers per year [3]. Reasons given for the growing number of slope tourers include the easy ascent, physical activity-related health promotion, no risk of avalanches on slopes, and social aspects [3]. This progress, however, often causes troubles with the lift companies because of safety risks through ascending slope tourers during daytime hours and descending slope tourers during nighttime hours [2]. Overall, little is known about injuries and risk factors in slope touring. In a preliminary study, Ruedl et al. investigated potential factors associated with injuries in slope touring [2]. More than 450 slope tourers (60.1\% males) with a mean age of $39.3 \pm 14.4$ years reported that they perform about $20.6 \pm 16.0$ slope tours per season mainly with a partner (48\%) and during the day (51\%) [2]. A total of 57 persons $(12.6 \%)$ reported that they have suffered at least one injury during slope touring that required medical care; this corresponds to a rate of six injuries per 1000 slope tours. Main causes of injury were falls (78\%) and collisions with another person (15\%), and the main injured body part was the knee (36\%) [2]. Slope tourers with an injury history were more likely to report wearing back protectors and to have experienced more falls during downhill skiing [2]. They were also more likely to report listening to music more often during downhill skiing and to consume alcohol more frequently in the hut compared to slope tourers without an injury history [2]. In a survey among slope tourers, participants reported to fear an injury mostly through a collision with intoxicated, descending skiers while ascending the mountain uphill or an accident with the cable winch of a snow groomer while skiing downhill on the slope during night [4]. As alcohol consumption is often associated with winter sports-related injuries [5], the aim of this study was to evaluate factors associated with alcohol intake among uninjured slope tourers.

\section{Methods}

Slope tourers were assessed at two different skiing huts ( $>750 \mathrm{~m}$ of ascent) in Tyrol, Austria. Assessments took place during daytime (9.00 a.m.-4.00 p.m.) and nighttime hours (5.30 p.m.-9.45 p.m.) in February and March 2014. The mean duration of completing the questionnaires was about 15-25 min. Inclusion criterion was the ascent of the person with skis. Eight persons cancelled the participation at an early stage and were therefore excluded. Before leaving the hut, participants were asked to perform an alcohol breath test with the LION FUEL CELL SENSOR 500 to measure their breath alcohol concentration; to avoid false-positive results, a time interval of at least $15 \mathrm{~min}$ after the last drink was assured before breathalyzing. 
Besides sociodemographic data (age, sex, BMI, education degree), participants were asked about their subjective skill level (beginner/intermediate, advanced, expert) according to Sulheim et al. [6] and risk-taking behavior (more cautious vs. more risky) according to Sulheim et al. [7] and Ruedl et al. [8], years of experience in ski touring, weekly frequency of ski touring (regularly = minimum one tour per week vs. irregularly), amount of persons in the group (alone vs. two persons vs. three and more persons), and ski helmet use. Additionally, participants had to answer questions about how frequently they consumed alcohol during the last five ski tours (never vs. once vs. several times vs. always), their perceived alcohol intake (Do you feel intoxicated? - not at all vs. little vs. moderate vs. strongly), and their estimated alcohol level (in \%o).

\section{Statistical Analysis}

Data are presented as means and standard deviations and as absolute and relative frequencies. Chi-square tests were used to compare the groups of slope tourers with and without alcohol intake regarding sex, education degree, time of the day (day vs. night), skill level, risk-taking behavior, helmet use, group size, and ski touring frequency. Mann-Whitney-U Tests were used to compare both groups (alcohol vs. no alcohol intake) regarding age, BMI, and years of experience. In addition, MannWhitney-U Tests were used to compare mean breath alcohol level between male and female slope tourers. One-way ANOVAs were used to calculate differences between mean alcohol level and perceived alcohol intake, and between mean breath alcohol level and alcohol consumption during the last five ski tours. Spearman correlation analyses were used to show relationships between estimated and measured breath alcohol level. All $p$-values were two-tailed and values of $p<0.05$ were considered to indicate statistical significance.

\section{Results}

A total of 328 slope tourers ( $45 \%$ females) with a mean age of $43.8 \pm 11.8$ years and a mean BMI of $23.0 \pm 2.9$ participated in this study. The majority of the slope tourers were advanced skiers $(55 \%)$ and performed their sport in a favored group size of two people $(75 \%)$.

In total, $187(57 \%)$ of slope tourers stated that they consumed alcohol in the hut. Mean-tested breath alcohol level was $0.24 \pm 0.17 \%$ (range: $0-1.32 \%$ ) which significantly differed from the mean estimated breath alcohol level of $0.18 \pm 0.12 \%$ o (range: $0-0.5 \%$ ) $(p<0.001)$. Male slope tourers had a significantly higher breath alcohol level than female slope tourers $(0.26 \pm 0.17$ vs. $0.22 \pm 0.15 \%$ o $p=0.014)$.

None of the slope tourers with alcohol intake felt strongly intoxicated. In total, $11(6 \%)$ participants felt moderately intoxicated with a tested mean alcohol level of 
$0.45 \pm 0.35 \%$ o, $50(27 \%)$ participants felt little intoxicated with a tested mean alcohol level of $0.29 \pm 0.17 \%$ o, and $126(67 \%)$ participants did not feel intoxicated at all with a tested mean alcohol level of $0.21 \pm 0.12 \%$. The subjective feeling of intoxication showed a significant difference between the three groups in terms of the tested breath alcohol level $(p<0.001)$. There was a strong, significant correlation between estimated and measured breath alcohol level $(r=0.854 ; p<0.001)$.

Regarding the alcohol consumption during the last five ski tours, one-way ANOVA showed that those participants who drank always $(N=44$; mean alcohol level of $0.32 \pm 0.22 \%$ ) or several times $(N=83$; mean alcohol level of $0.24 \pm 0.14 \%$ o had significantly higher mean alcohol levels than those who drank just once $(N=46$; mean alcohol level of $0.18 \pm 0.11 \%$ o $)$ or never $(N=12$; mean alcohol level of $0.20 \pm 0.12 \%$ o $(p<0.001)$.

Table 1 shows two groups of slope tourers divided into an Alcohol Intake Group (AIG) and a No-Alcohol Intake Group (NAIG). AIG significantly differed from NAIG regarding sex, BMI, ski touring experience, and ski helmet use (see Table 1).

\section{Discussion}

The aim of this study was to evaluate factors associated with alcohol intake among slope tourers who visited mountain top huts in Austria in the winter of 2014. In total, $57 \%$ of the slope tourers stated that they consumed alcohol in the hut. Based on data collected from self-report questionnaires, male sex, higher BMI, more ski touring experience, and less ski helmet use were significantly associated with alcohol intake among slope tourers. In addition, male slope tourers had a significantly higher breath alcohol level than female slope tourers and mean-tested breath alcohol level was significantly higher (about $25 \%$ ) compared to the mean estimated breath alcohol level.

The cohort of slope tourers in the current study with a mean age of about 44 years consisted primarily of males (55\%). In comparison, in the study on slope tourers by Ruedl et al. $60 \%$ were males and mean age was about 39 years [2]. Furthermore, the high number of slope tourers with a self-estimated advanced or expert skiing skill level and the favored group size of two persons remain comparable throughout various studies $[2,4,9]$.

The high number of slope tourers with alcohol consumption in this study must be viewed with caution as it needs to be taken into account that assessments were conducted in the huts. Since not all slope tourers visit the huts, a much lower proportion of alcohol consumption may be observed if tests were conducted of slope tourers in the parking area.

In the current study, $66 \%$ of slope tourers who consumed alcohol were males and the mean breath alcohol level was significantly higher among male compared to female slope tourers. Those sex differences regarding alcohol consumption are widely known $[10,11]$ and occur even in adolescence [12]. Schmid stated that in young adults aged 19-20 years, $62 \%$ of males and $32 \%$ of females consume alcohol 
Table 1 Characteristics of factors associated with alcohol intake among slope tourers

\begin{tabular}{|c|c|c|c|c|}
\hline & & AIG & NAIG & $p$ \\
\hline \multirow[t]{2}{*}{$\operatorname{Sex}, N^{\mathrm{a}}(\%)$} & Female & $63(34)$ & $86(61)$ & \multirow[t]{2}{*}{$<0.001 * *$} \\
\hline & Male & $124(66)$ & $54(39)$ & \\
\hline $\mathrm{BMI}($ mean $\pm \mathrm{SD})$ & & $23.3 \pm 2.9$ & $22.6 \pm 2.8$ & $0.007 * *$ \\
\hline Age $($ mean \pm SD $)$ & & $44.5 \pm 11.3$ & $42.8 \pm 12.4$ & 0.172 \\
\hline \multirow[t]{4}{*}{$\begin{array}{l}\text { Education/degree, } N^{\mathrm{a}} \\
(\%)\end{array}$} & $\begin{array}{l}\text { Compulsory school } \\
\text { graduation/apprenticeship }\end{array}$ & $55(29)$ & $40(28)$ & \multirow[t]{4}{*}{0.152} \\
\hline & A level & $50(27)$ & $24(17)$ & \\
\hline & University & $66(35)$ & $50(43)$ & \\
\hline & Other education & $16(9)$ & $17(12)$ & \\
\hline \multirow{2}{*}{$\begin{array}{l}\text { Ski touring frequency, } \\
N(\%)\end{array}$} & Regularly: min 1/week & $129(69)$ & $61(43)$ & \multirow[t]{2}{*}{0.116} \\
\hline & Unregularly & $58(31)$ & $80(57)$ & \\
\hline \multirow[t]{3}{*}{ Group size $^{\mathrm{a}}, N(\%)$} & Alone & $34(18)$ & $27(19)$ & \multirow[t]{3}{*}{0.561} \\
\hline & Two people & $100(54)$ & $82(59)$ & \\
\hline & Three or more & $52(28)$ & $30(22)$ & \\
\hline \multirow[t]{3}{*}{ Skill level, $N(\%)$} & Beginner/intermediate & $24(13)$ & $27(19)$ & \multirow[t]{3}{*}{0.306} \\
\hline & Advanced & $142(76)$ & $104(74)$ & \\
\hline & Expert & $21(11)$ & $10(7)$ & \\
\hline $\begin{array}{l}\text { Ski touring experience } \\
\text { [years] (mean } \pm \mathrm{SD})\end{array}$ & & $15.8 \pm 11.8$ & $10.7 \pm 9.2$ & $<0.001 * *$ \\
\hline \multirow[t]{2}{*}{ Time of day, $N(\%)$} & Day & $70(37)$ & $61(44)$ & \multirow[t]{2}{*}{0.262} \\
\hline & Night & $117(63)$ & $79(56)$ & \\
\hline \multirow[t]{2}{*}{ Helmet, $N(\%)$} & Yes & $68(36)$ & $70(50)$ & \multirow[t]{2}{*}{$0.019 *$} \\
\hline & No & $119(64)$ & $71(50)$ & \\
\hline \multirow{2}{*}{$\begin{array}{l}\text { Risk-taking behavior }{ }^{\mathrm{a}}, \\
N(\%)\end{array}$} & More cautious & $147(80)$ & $117(84)$ & \multirow[t]{2}{*}{0.347} \\
\hline & More risky & $38(20)$ & $23(16)$ & \\
\hline
\end{tabular}

$A I G$ alcohol intake group, $N A I G$ no-alcohol intake group

$* p \leq 0.05, * * p \leq 0.01$

a Due to missing data, the number of participants does not sum up to $N=328$

[12]. In accordance, it has been reported that mean blood alcohol concentrations are significantly higher in a cohort of uninjured male skiers and snowboarders compared to uninjured female skiers and snowboarders [13].

Mean breath alcohol level of slope tourers was $0.24 \pm 0.17 \%$ o with a range from $0-1.32 \%$. In comparison, Li et al. stated that in biking, a blood alcohol concentration of $0.02 \mathrm{~g} / \mathrm{dL}(\hat{=} 0.16 \%$ ) raises the risk of a fatal or serious injury about 5.6 times and a blood alcohol concentration of $0.08 \mathrm{~g} / \mathrm{dL}(\hat{=} 0.65 \%)$ increases the risk of a fatal or serious injury about 20.2 times [14]. Gaudio et al. detected in a cohort of 200 skiers and snowboarders with a major injury trauma that a high blood concentration was present in $43 \%$ of patients [5]. In addition, in the study by Ruedl et al., slope tourers with an injury history reported greater alcohol consumption in the hut compared to slope tourers without an injury history [2]. Therefore, one could assume that alcohol consumption would be a major risk factor for injuries on ski slopes. However, to evaluate the impact of alcohol consumption on injury risk 
among winter sport participants, a case-control study design comparing the breath or blood alcohol levels of injured to uninjured persons would be necessary. Earlier studies using such a study design, however, found no significant differences with respect to mean blood alcohol concentration between injured and uninjured winter sport participants $[13,15,16]$. In contrast, Burtscher et al. stated that alcohol consumption on the skiing day was a risk factor for falls in skiers and snowboarders [17]. This might be due to the fact that alcohol consumption impairs the central nervous system function, resulting in decrements in cognitive function and motor skills [18]. Although a fall does not imply an injury, self-inflicted falls are the major cause for injuries during skiing and snowboarding [17].

The present study found that slope tourers significantly underestimated their breath alcohol level considering that the mean-tested breath alcohol level was about $25 \%$ higher compared to the mean estimated breath alcohol level. Underestimation of alcohol intoxication might be a risk factor for a fall causing an injury on the ski slope.

Regarding participants' perceptions of alcohol consumption, none of the slope tourers with alcohol intake reported feeling strongly intoxicated, and a decreasing perception of the individual alcohol level was significantly associated with a decreasing mean-tested breath alcohol level. This result implies that many of the slope tourers may be unaware of the fact that there is sufficient alcohol in their system to potentially cause impairments. Even low doses of alcohol significantly produced more incorrect reactions during a peripheral vision test [19] and might have further impacts on athletic and cognitive performance [18, 20].

In this study, a higher frequency of alcohol consumption during the last five ski tours was significantly associated with a higher mean breath alcohol level indicating a possible association between drinking frequency during ski tours and level of alcohol intoxication. In addition, slope tourers with alcohol consumption reported significantly higher BMIs compared to those without alcohol intake. This might be due to the fact that studies reported positive findings between alcohol intake and weight gain $[21,22]$.

Slope tourers with and without alcohol consumption did not differ in this study with regard to age, group size, educational degree, self-reported skill level, and risktaking behavior. Group size or peer group are likely to influence alcohol consumption as studies have shown that team athletes consume more alcohol than individual athletes [10, 23, 24]; however, this result was not reflected in the present study.

Slope tourers with alcohol intake showed a significantly higher mean ski touring experience (16 vs. 11 years) compared to those who did not drink alcohol in the hut. Although studies indicate that sport participation is associated with alcohol use [25], to our knowledge, no literature is available concerning the years of sport participation and alcohol intake.

Slope tourers with alcohol intake were significantly less likely to report wearing a ski helmet compared to tourers with no alcohol intake (36 vs. 50\% helmet use). This might be the result of the duration in sport participation because AIG slope tourers have engaged in their sport over a longer period of time (16 years vs. 11 years). Since helmet use rates have increased significantly over the last decade, the NAIG 
might have started slope touring with helmet right from the beginning. As Ruedl et al. presented, the head was involved in $14 \%$ of injuries among slope tourers [2]. A helmet would be a meaningful safety equipment to reduce head injury risk [7].

In conclusion, about $60 \%$ of the interviewed slope tourers consumed alcohol in the hut. Male sex, a higher BMI, a longer ski touring experience, and less ski helmet use were significantly associated with alcohol intake among slope tourers. In addition, male slope tourers had a significantly higher breath alcohol level than female slope tourers and mean-tested breath alcohol level was significantly higher compared to the mean estimated breath alcohol level by about $25 \%$.

Obtained results require preventive interventions to reduce alcohol consumption among slope tourers. The interventions should be especially addressed to the group of male slope tourers with over 10 years of experience in ski touring and an age of about 40 years.

\section{References}

1. Burtscher M, Bodner T, Burtscher J et al (2013) Life-style characteristics and cardiovascular risk factors in regular downhill skiers: an observational study. BMC Publ Health 13:788. doi:10.1186/1471-2458-13-788

2. Ruedl G, Pocecco E, Kopp M et al (2015) Verletzungshäufigkeit und unfallursachen beim pistentourengehen—eine pilotstudie. Sportverletz Sportschaden 29(01):46-50. doi:10.105 5/s-0034-1399181

3. Essl J, Koch W (2011) Pistentouren im Großraum Innsbruck: 3-10

4. Pröbstl U (2012) Skitourengeher auf pisten—neue zielgruppe oder trainingsvariante? Mountainmanager (4):54-55

5. Gaudio RM, Barbieri S, Feltracco P et al (2010) Impact of alcohol consumption on winter sports-related injuries. Med Sci Law 50(3):122-125

6. Sulheim S, Ekeland A, Bahr R (2007) Self-estimation of ability among skiers and snowboarders in alpine skiing resorts. Knee Surg Sports Traumatol Arthrosc 15(5):665-670. doi:10.1007/ s00167-006-0122-x

7. Sulheim S, Holme I, Ekeland A et al (2006) Helmet use and risk of head injuries in alpine skiers and snowboarders. JAMA 295(8):919-924. doi:10.1001/jama.295.8.919

8. Ruedl G, Pocecco E, Sommersacher R et al (2010) Factors associated with self-reported risktaking behaviour on ski slopes. Br J Sports Med 44(3):204-206. doi:10.1136/bjsm.2009.066779

9. Kopp M, Wolf M, Ruedl G et al (2016) Differences in sensation seeking between alpine skiers, snowboarders and ski tourers. J Sports Sci Med 15(1):11-16

10. Watten RG (1995) Sports, physical exercise and use of alcohol. Scand J Med Sci Sports 5(6):364-368

11. Greenfield TK, Room R (1997) Situational norms for drinking and drunkenness: trends in the US adult population, 1979-1990. Addiction 92(1):33-47

12. Schmid H (2002) Sport, alkohol, tabak und illegale drogen in der entwicklung von jugendlichen $\mathrm{zu}$ jungen erwachsenen. Zeitschrift für Gesundheitspsychologie 10(1):36-48. doi:10.1026//0943-8149.10.1.36

13. Salminen S, Pohjola J, Saarelainen P et al (1996) Alcohol as a risk factor for downhill skiing trauma. J Trauma 40(2):284-287

14. Li G, Shahpar C, Soderstrom CA et al (2000) Alcohol use in relation to driving records among injured bicyclists. Accid Anal Prev 32(4):583-587 
15. Bouter LM (ed) (1988) Alcohol consumption and injury risk in downhill skiing: Injury risk in downhill skiing. Results from an etiological case-control study conducted among Dutch skiers. In: Sportwetenschappelijke onderzoekingen, vol 14. De Vrieseborch, Haarlem, pp 89-107

16. Made C, Elmqvist L (1996) Downhill Skiing injuries in Lapland, Sweden: a survey including alcohol monitoring and one-year follow-up. In: Mote CD, Johnson RJ, Hauser W et al (eds) Skiing Trauma and Safety, vol 10. ASTM International, West Conshohocken, PA, pp 98-98-6

17. Burtscher M, Pühringer R, Werner I et al (2010) Gender-specific effects of smoking and alcohol consumption on the risk of falling in downhill skiers. J ASTM Int 7(7):102815. doi:10.1520/ JAI102815

18. Shirreffs SM, Maughan RJ (2006) The effect of alcohol on athletic performance. Curr Sports Med Rep 5(4):192-196

19. Langer P, Holzner B, Magnet W et al (2005) Hands-free mobile phone conversation impairs the peripheral visual system to an extent comparable to an alcohol level of 4-5 g $100 \mathrm{ml}$. Hum Psychopharmacol 20(1):65-66. doi:10.1002/hup.654

20. Barnes MJ (2014) Alcohol: impact on sports performance and recovery in male athletes. Sports Med 44(7):909-919. doi:10.1007/s40279-014-0192-8

21. Sayon-Orea C, Martinez-Gonzalez MA, Bes-Rastrollo M (2011) Alcohol consumption and bodyweight:asystematicreview.NutrRev69(8):419-431.doi:10.1111/j.1753-4887.2011.00403.x

22. Schrieks IC, Stafleu A, Griffioen-Roose S et al (2015) Moderate alcohol consumption stimulates food intake and food reward of savoury foods. Appetite 89:77-83. doi:10.1016/j. appet.2015.01.021

23. Lorente FO, Souville M, Griffet J et al (2004) Participation in sports and alcohol consumption among French adolescents. Addict Behav 29(5):941-946. doi:10.1016/j.addbeh.2004.02.039

24. Kulesza M, Grossbard JR, Kilmer J et al (2014) Take one for the team? Influence of team and individual sport participation on high school athlete substance use patterns. J Child Adolesc Subst Abuse 23(4):217-223. doi:10.1080/1067828X.2013.786928

25. Kwan M, Bobko S, Faulkner G et al (2014) Sport participation and alcohol and illicit drug use in adolescents and young adults: a systematic review of longitudinal studies. Addict Behav 39(3):497-506. doi:10.1016/j.addbeh.2013.11.006

Open Access This chapter is distributed under the terms of the Creative Commons AttributionNoncommercial 2.5 License (http://creativecommons.org/licenses/by-nc/2.5/) which permits any noncommercial use, distribution, and reproduction in any medium, provided the original author(s) and source are credited.

The images or other third party material in this chapter are included in the work's Creative Commons license, unless indicated otherwise in the credit line; if such material is not included in the work's Creative Commons license and the respective action is not permitted by statutory regulation, users will need to obtain permission from the license holder to duplicate, adapt or reproduce the material. 